\title{
Vaginal microbicides for reducing the risk of sexual acquisition of HIV infection in women: systematic review and meta-analysis
}

\author{
Jael Obiero ${ }^{1,2^{*}}$, Peter G Mwethera', Gregory D Hussey ${ }^{3,4}$ and Charles S Wiysonge ${ }^{3,4}$
}

\begin{abstract}
Background: Each year more than two million people are newly infected with HIV worldwide, a majority of them through unprotected vaginal sex. More than half of new infections in adults occur in women. Male condoms and male circumcision reduce the risk of HIV acquisition; but the uptake of these methods is out of the control of women. We therefore aimed to determine the effectiveness of vaginal microbicides (a potential female-controlled method) for prevention of sexual acquisition of HIV in women.
\end{abstract}

Methods: We conducted a comprehensive search of peer-reviewed and grey literature for publications of randomised controlled trials available by September 2012. We screened search outputs, selected studies, assessed risk of bias, and extracted data in duplicate; resolving differences by discussion and consensus.

Results: We identified 13 eligible trials that compared vaginal microbicides to placebo. These studies enrolled 35,905 sexually active HIV-negative women between 1996 and 2011; in Benin, Cameroon, Cote d'Ivoire, Ghana, Kenya, Malawi, Nigeria, South Africa, Tanzania, Uganda, Zambia, Zimbabwe, India, Thailand, and the United States of America. A small trial of 889 women found that tenofovir (a nucleotide reverse transcriptase inhibitor) significantly reduces the risk of HIV acquisition (risk ratio [RR] 0.63, 95\% confidence intervals [CI] 0.43 to 0.93). Effectiveness data are not yet available from follow-up tenofovir trials being conducted in South Africa, Uganda, and Zimbabwe ( 1 trial) and multiple sites in South Africa (1 trial). We found no evidence of a significant effect for nonoxynol-9 (5 trials), cellulose sulphate (2 trials), SAWY (2 trials), Carraguard (1 trial), PRO 2000 (2 trials), and BufferGel (1 trial) microbicides. The pooled RR for the effect of current experimental vaginal microbicides on HIV acquisition in women was $0.97,95 \% \mathrm{Cl} 0.87$ to 1.08 . Although study results were homogeneous across the different drug classes (heterogeneity $\mathrm{P}=0.17, \mathrm{I}^{2}=27 \%$ ), the overall intervention effect was not statistically significant. Nonoxynol-9 significantly increased the risk of having adverse genital lesions but no other microbicide led to significant increases in adverse events.

Conclusions: There is not enough evidence at present to recommend vaginal microbicides for HIV prevention. Further high-quality research is needed to confirm the beneficial effects of tenofovir as well as continue the development and testing of new microbicides.

\footnotetext{
* Correspondence: obierojatina@yahoo.com

${ }^{1}$ Department of Reproductive Health and Biology, Institute of Primate

Research, Karen Road, Nairobi, Kenya

${ }^{2}$ Department of Medical Microbiology, University of Nairobi, Off Ngong Road,

Nairobi, Kenya

Full list of author information is available at the end of the article
}

\section{Biomed Central}

(c) 2012 Obiero et al.; licensee BioMed Central Ltd. This is an Open Access article distributed under the terms of the Creative Commons Attribution License (http://creativecommons.org/licenses/by/2.0), which permits unrestricted use, distribution, and reproduction in any medium, provided the original work is properly cited. 


\section{Background}

Antiretroviral drugs are among the greatest medical breakthroughs of the last three decades. However, they have limitations which include (but are not limited to) the emergence of multi-drug-resistant HIV virus strains, toxicity, difficult treatment regimens, and inadequate pharmacology, bioavailability and tissue distribution [1-3]. Therefore, prevention of new HIV infections remains the backbone of efforts to control the HIV pandemic $[1,4,5]$. The male condom protects against acquisition and transmission of HIV, but its use requires agreement by both sexual partners. Recently, early initiation of antiretroviral therapy was shown to be effective in reducing the risk of sexual transmission of HIV [6]. In addition medical male circumcision reduces the risk of HIV acquisition in men $[7,8]$, but evidence is lacking on whether male circumcision confers protection for women; who currently account for more than half of the 34 million people estimated to be living with HIV worldwide [1]. The need for female-controlled HIV prevention strategies has been recognised, and the current strategies being researched include vaginal microbicides [9]. Microbicides are compounds that when inserted vaginally would (at least in theory) act to prevent acquisition and or transmission of HIV during sexual intercourse. Most of the current microbicide research is undertaken in sub-Saharan Africa and Southeast Asia, but an effective microbicide will undoubtedly be used worldwide to prevent the sexual acquisition and or transmission of HIV. It has been estimated that even a partially effective microbicide could prevent millions of new HIV infections each year throughout the world [10]. In the absence of an effective prophylactic HIV vaccine, the development of a safe and effective microbicide is critical. This review aimed to determine the effectiveness of vaginal microbicides in preventing sexual acquisition of HIV infection by women.

\section{Methods}

We undertook this systematic review according to standard Cochrane methods [11]. We conducted a comprehensive search of electronic databases for relevant randomised controlled trials and systematic reviews published by September 2012. The databases searched were the Cochrane Central Register of Controlled Trials (CENTRAL), Medline, Embase, Web of Science, NLM Gateway, AIDS Education Global Information System, ClinicalTrials.gov, the World Health Organization (WHO) International Clinical Trials Registry Platform, Cochrane Database of Systematic Reviews (CDSR), and York Database of Abstracts of Reviews of Effectiveness (DARE). We supplemented the search by screening bibliographies of identified articles and proceedings of international AIDS conferences, and contacting relevant experts at WHO and the Joint United Nations Programme on HIV/AIDS (UNAIDS). We searched for all relevant studies regardless of language or publication status.

Two authors (Jael Obiero and Charles Wiysonge) independently assessed study eligibility, risk of bias in included studies, and extracted data; with disagreements resolved by discussion and consensus. Eligible studies were randomised controlled trials in which sexually active HIV-negative women from any setting were randomly allocated to a vaginal microbicide compared to a placebo or no intervention. All included studies were approved by relevant institutional ethical review boards in specific countries and all participants provided written informed consent. We have summarised the search and selection process for this review in Figure 1.

Our outcome of interest was new HIV infection; determined using internationally accepted diagnostic criteria.

We used the Cochrane Collaboration's Review Manager 5.1 (http://ims.cochrane.org/RevMan) for statistical analyses. We expressed each study result as a risk ratio (RR) with its 95\% confidence intervals (CI) and conducted meta-analysis by analysing trial participants in groups to which they were randomised, regardless of which or how much treatment they actually received. Despite the excellent mathematical properties of the odds ratio (OR), we did not choose it to measure study results in our analyses because the $\mathrm{OR}$ and $\mathrm{RR}$ differ considerably when control group risks are high (as was the case in this review) and effects are large. A misinterpretation of the OR in such a situation would lead to an overestimation of the intervention effect. There exist published examples of situations where authors have misinterpreted the OR from meta-analyses as if they were $R R$, leading to overestimation of intervention effects [11].

In meta-analyses, it is important to measure the degree to which the results of studies are consistent. Inconsistency in study results, known as statistical heterogeneity, is a consequence of clinical and or methodological differences among studies. Statistical heterogeneity manifests itself in the observed treatment effects being more different from each other than one would expect due to random error (or chance) alone. We used the Cochran's $\mathrm{Q}$ test to assess statistical heterogeneity between study results, defining statistical significance at the $10 \%$ alpha level $[11,12]$. Q is a chi-squared statistic with "degrees of freedom" equals to "number of studies" minus 1 . The statistic is calculated as the weighted sum of the squared differences between individual study effects and the pooled effect across the included studies, with the weights defined by the model of meta-analysis used i.e. fixed effect or random-effects. Q assesses whether observed differences in results are compatible with 


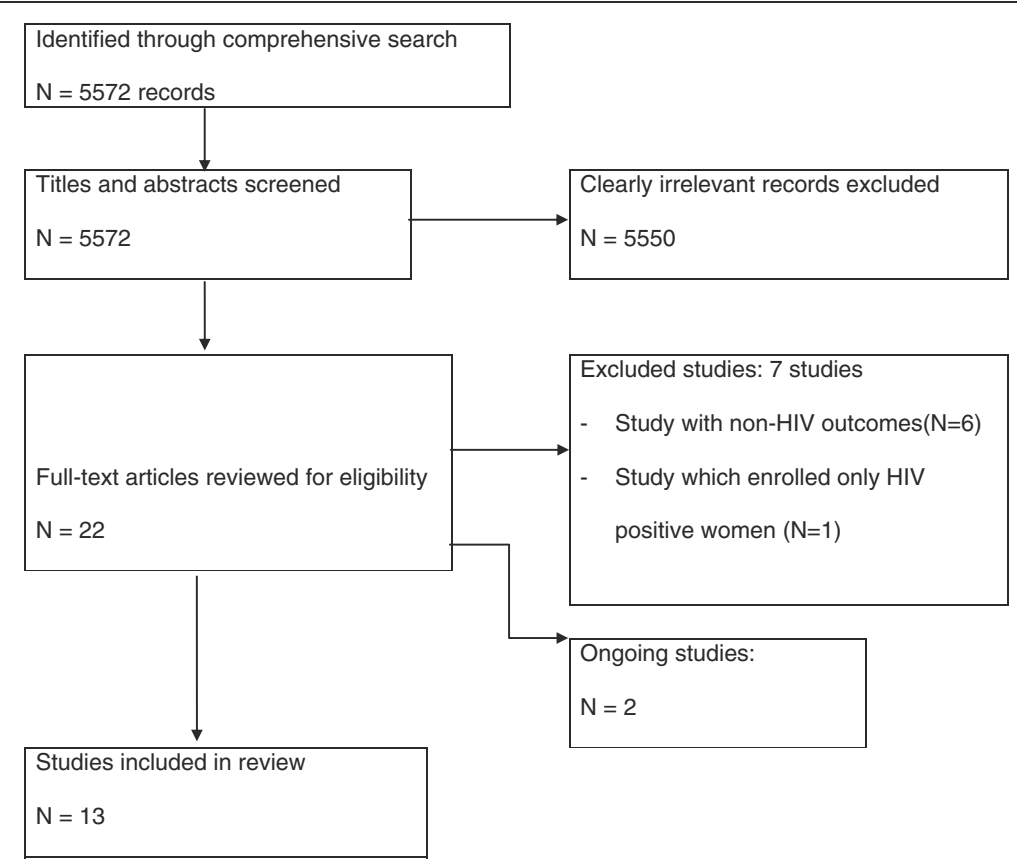

Figure 1 Flow chart of identification and selection of studies for inclusion.

chance alone. A low P value (or a large chi-squared statistic relative to its degrees of freedom) provides evidence of significant statistical heterogeneity of intervention effects [11,12]. In addition, we used the Higgins' Isquared test to quantify inconsistency in the effects of microbicides across the studies included in the metaanalysis [13]. The I-squared test statistic describes the percentage of the variability in effect estimates that is due to true differences between studies rather than chance.

There was no significant statistical heterogeneity between trial results $\left(X^{2}=17.72\right.$ [13 degrees of freedom], $\mathrm{P}=0.17 ; \mathrm{I}^{2}=27 \%$ ), and we combined the results using fixed effect meta-analysis [11,12]. However we also conducted a random-effects meta-analysis [14], in order to document the robustness of our findings to the method of meta-analysis [11]. The pooled effect from the fixedeffect method is considered to be a typical intervention effect from the studies included in the meta-analysis; implying that observed differences among study results are caused exclusively by chance. Random-effects meta-analysis, on the other hand, assumes that estimated study effects are not identical; but differ at random, following a normal distribution [14]. In addition, we sub-grouped the trials by type of microbicide under investigation.

\section{Results}

Of 22 potentially eligible studies, 13 met our inclusion criteria [15-27] and two are ongoing [28,29]. The remaining seven studies were excluded; six of them enrolled HIVnegative women but did not report HIV incidence [30-35] and the seventh one enrolled only HIV positive women [36]. The seven excluded trials were set up to assess the effects of vaginal microbicides on the incidence of nonHIV sexually transmitted infections [30-36].

The 13 included randomised controlled trials, involving seven microbicides, had either been conducted to term (three Nonoxynol-9, one BufferGel and 0.5\% PRO 2000, one Carraguard, and one tenofovir trial) or stopped early due to safety concerns (one Nonoxynol-9 and two cellulose sulphate trials) or insufficient rate of HIV infection and low likelihood of showing a protective effect (one Nonoxynol-9, one 2\% PRO 2000, and two SAVVY trials) (Table 1). The studies enrolled 35,905 sexually active HIV negative women between 1996 and 2011; in Kenya [15,19], Cameroon [16,17], Cote d'Ivoire [18], Benin [18,24], Ghana [23], Malawi [26], Nigeria [20,21], South Africa [17,22,24-27], Tanzania [22], Uganda [22], Zambia [22,26], Zimbabwe [26], Thailand [18], India [24], and the United States of America [26].

A small proof-of-concept randomised controlled trial found that tenofovir (a nucleotide reverse transcriptase inhibitor) significantly reduces the risk of HIV acquisition (889 women: RR 0.63, 95\% CI 0.43 to 0.93). Despite the small sample size, the results were statistically significant $(P=0.02)$ [25]. Effectiveness data are not yet available from the second tenofovir trial that enrolled 5000 women (in South Africa, Uganda, and Zimbabwe) and was stopped early due to low likelihood of showing a protective effect [28]. Two of the five arms in this trial were designed to test the effectiveness of the tenofovir 
Table 1 A summary of characteristics of included studies

\begin{tabular}{|c|c|c|c|}
\hline Author & Method & Participants and settings & Interventions/control \\
\hline Kreiss 1992 [15] & Unblinded RCT & 138 female sex workers Nairobi, Kenya & 1000 mg N-9 sponge/placebo \\
\hline Richardson 2001 [19] & Double blind RCT & 278 female sex workers, Mombasa, Kenya & $52.5 \mathrm{mg} \mathrm{N}-9 \mathrm{gel} /$ placebo \\
\hline Roddy 1998 [17] & Double blind RCT & 1292 female sex workers, Cameroon & 70 mg N-9 film/placebo \\
\hline Roddy 2002 [16] & Unblinded RCT & $\begin{array}{l}1251 \text { women (non sex workers) from clinics or } \\
\text { pharmacy, Cameroon }\end{array}$ & $100 \mathrm{mg} \mathrm{N}-9 \mathrm{gel} / \mathrm{No}$ intervention \\
\hline Van Damme 2002 [18] & Triple blind RCT & $\begin{array}{l}892 \text { women sex workers from Benin, Cote d'Ivoire, } \\
\text { South Africa, Thailand }\end{array}$ & $52.5 \mathrm{mg} \mathrm{N}$-9/placebo \\
\hline Halpern 2008 [21] & Double blind RCT & $\begin{array}{l}1644 \text { women from bars, market, other common } \\
\text { gathering areas, Lagos and Port Harcourt, Nigeria }\end{array}$ & $6 \%$ CS gel/placebo \\
\hline Van Damme 2008 [24] & Double blind RCT & $\begin{array}{l}1428 \text { women, South Africa, Uganda, Benin and } \\
\text { India (Chennai, Bangalore) }\end{array}$ & $6 \%$ CS gel/placebo \\
\hline Felblum 2008 [20] & Double blind RCT & $\begin{array}{l}2153 \text { women from local market areas, bars hostels, } \\
\text { military barracks and colleges, Lagos and Ibadan, } \\
\text { Nigeria }\end{array}$ & 1.0\% C31G (SAWY) gel/placebo \\
\hline Peterson 2007 [23] & Double blind RCT & $\begin{array}{l}2142 \text { women from high HIV transmission areas } \\
\text { including markets, bars, hotels, Accra and Kumasi, } \\
\text { Ghana }\end{array}$ & 1\% C31G (SAWY) gel/placebo \\
\hline Skoler-Karpoff 2008 [27] & Double blind RCT & $\begin{array}{l}\text { 6,202 women from local health clinics, malls, churches, } \\
\text { taxi ranks, other community venues, University of Cape } \\
\text { Town, University of Limpopo-Medunsa campus } \\
\text { Ga-Rankuwa and Medical Research Council, Durban, } \\
\text { South Africa }\end{array}$ & Carraguard gel/placebo \\
\hline Abdul Karim 2011[26] & RCT Double blind & $\begin{array}{l}3101 \text { women in Malawi, South Africa, Zambia, Zimbawe, } \\
\text { USA }\end{array}$ & BufferGel/ 0.5\% PRO2000/placebo \\
\hline McCormack 2010 [22] & RCT Double blind & $\begin{array}{l}\text { 6,651 women, three sites in South Africa; Mwanza, } \\
\text { Tanzania; Entebbe, Uganda; Mazambuka, Zambia }\end{array}$ & 0.5\% PRO2000 gel/placebo \\
\hline Abdul Karim 2010 [25] & RCT Double blind & $\begin{array}{l}1085 \text { at urban and rural clinic, Kwa-Zulu Natal, } \\
\text { South Africa }\end{array}$ & $1 \%$ tenofovir gel/placebo \\
\hline
\end{tabular}

CS, cellulose sulphate; $N-9$, nonoxynol-9; RCT, randomised controlled trials; USA, United States of America.

gel and enrolled 2000 women [28]. The third tenofovir trial started in October 2011, with data collection expected to end in May 2014 [29]. The latter is planned to assess the safety and effectiveness of $1 \%$ tenofovir gel among approximately 2900 sexually active women at high risk for sexual acquisition of HIV in South Africa.

We found no evidence of a significant effect on HIV acquisition for nonoxynol-9 (5 trials, $\mathrm{N}=3592$; $\mathrm{RR} 1.13$, 95\% CI 0.91 to 1.14 ; [15-19]), cellulose sulphate (2 trials, $\mathrm{N}=3,069$ : RR $1.20,95 \%$ CI 0.74 to 1.95 ; [21,24]), SAVVY (2 trials, $\mathrm{N}=4,295$ : $\mathrm{RR} 1.38,95 \% \mathrm{CI} 0.79$ to 2.41; [20,23]), Carraguard ( 1 trial, $\mathrm{N}=6,202: \mathrm{RR} 0.89,95 \% \mathrm{CI}$ 0.71 to 1.11 ; [27]), PRO 2000 (2 trials, $\mathrm{N}=12,486$ : RR 0.93, 95\% CI 0.77 to $1.14,[22,26]$ ), and BufferGel (1 trial, $\mathrm{N}=1,546$ : RR 1.05, 95\% CI 0.73 to 1.52; [26]) (Figure 2).

The pooled RR for the 13 trials was 0.97 (95\% CI 0.87 to 1.08) when we used fixed effect meta-analysis, and 0.98 (95\% CI 0.86 to 1.12 ) when we used the random-effects method. Although the confidence intervals were wider with the random-effects method, the findings of our review are not sensitive to the method of meta-analysis.

The most common adverse event reported by trials was genital lesion (laceration, abrasion, ulceration, irritation) with the highest risk occurring in the nonoxynol-9 trials (5 trials, $\mathrm{N}=3592$ ). In the other trials this event was reported to be similar in both the microbicide and placebo arms.

The randomisation sequence was adequately generated and the allocation was adequately concealed in all 13 studies. We therefore think there was no selection bias in any of the included studies. In two studies $[15,16]$ blinding was not done since an appropriate placebo could not be manufactured; hence high risk of bias. Seven trials $[15,19-24]$ were stopped early due to datadependent processes. Due to the early discontinuation, four of the studies had a very high attrition rate: $10 \%$ in a cellulose sulphate trial [24], 16\% in a SAVVY trial [23], $17 \%$ in a nonoxynol-9 trial [15], and $30 \%$ in another cellulose sulphate trial [21]. In addition, loss to follow up was high in three nonoxynol-9 trials conducted to term i.e. $12 \%$ in the trial by Rody and colleagues among non-sex workers in Cameroon [16], 20\% in the trial by Rody and co-workers among female sex workers in Cameroon [17], and $22.6 \%$ in a trial by Van Damme and co-workers among female sex workers in Benin, Cote d'Ivoire, South Africa and Thailand [18]. We have rated the risk of bias due to incomplete outcome data for each 
of these studies as high. The proportion of participants lost to follow up was unclear in one nonoxynol-9 study [19]. The remaining studies had losses to follow-up ranging from $3 \%$ to $7 \%[20,22,25-27]$. We have summarised the risk of bias in included trials in Figure 3.

\section{Discussion}

To date, 13 randomised controlled trials involving seven different vaginal microbicides (namely: nonoxynol-9, SAVVY, cellulose sulphate, carraguard, PRO 2000, BufferGel and tenofovir) have either been conducted to term 


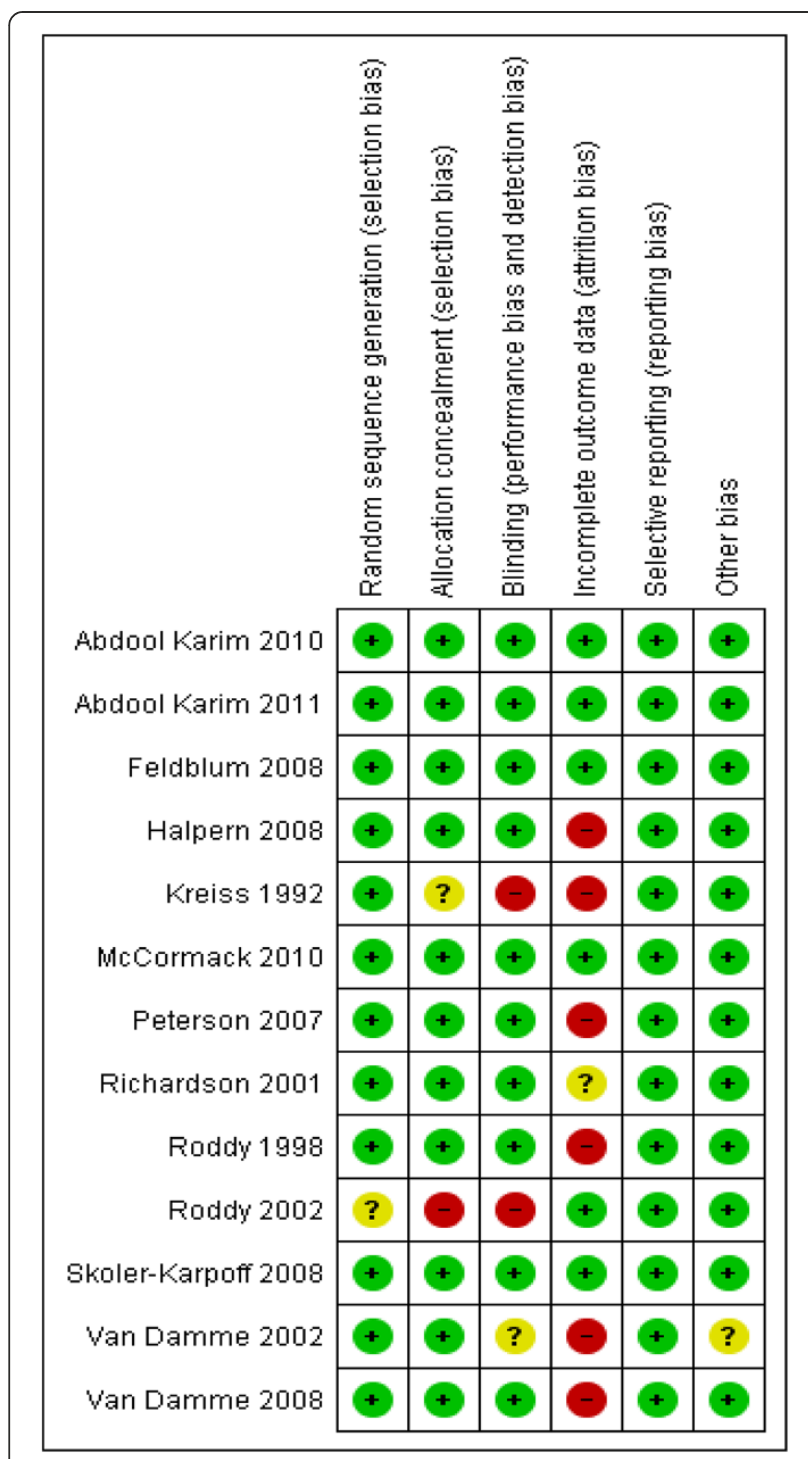

Figure 3 The risk of bias in currently available randomised controlled trials that have assessed the effect of vaginal microbicides for prevention of HIV acquisition in women.

or stopped early at the recommendation of the respective data and safety monitoring boards. Overall, the included studies which enrolled a total of 35,905 HIV-negative heterosexual women show no evidence of an effect of vaginal microbicides on the risk of HIV acquisition. The pooled risk ratio was 0.97 (95\% CI 0.87 to 1.08) for fixed-effect and 0.98 (95\% CI 0.86 to 1.12 ) for randomeffects meta-analysis $\left(\mathrm{I}^{2}=27 \%\right)$. However, one small study that enrolled 889 women in South Africa suggests that a vaginal microbicide containing tenofovir (an antiretroviral drug belonging to the class of nucleotide reverse transcriptase inhibitors) may be effective in reducing the risk of HIV acquisition in heterosexual women. The relatively small sample size and the small number of study sites may restrict the broad generalisability of the finding that tenofovir reduces the risk of HIV acquisition in heterosexual women.

The main strengths of our systematic review are the comprehensive search for published and unpublished studies in multiple databases and contact with relevant organisations and experts, quantitative synthesis of all currently available data, and sensitivity analyses to investigate the sensitivity of our findings to the method of meta-analysis. In general, the $\mathrm{Q}$ statistic that we used to assess for heterogeneity in trial results has low power when studies included in a meta-analysis have small sample size or are few in number. This implies that, although a statistically significant result indicates substantial inconsistency in study effects, a non-significant result does not necessarily mean that there is no heterogeneity of effects $[11,13]$. Therefore to make our findings more secure, despite the finding of no significant statistical heterogeneity of effects, we conducted and reported both fixed- effect and random-effects meta-analyses [12,14]. In addition, it has been argued that statistical heterogeneity is inevitable in a meta-analysis; given that there will always be clinical and or methodological differences (however small) between studies included in the meta-analysis [13]. We therefore used the Higgins' I-squared statistic to quantify the heterogeneity of intervention effects across included studies, even though the Q statistic did not detect significant statistical heterogeneity. The low I-squared value (i.e. 27\%) reassured us that heterogeneity did not have a significant impact on the pooled effect estimate $[11,13]$.

To the best of our knowledge, although other microbicide reviews have been conducted [37-42], our review is the most comprehensive synthesis of existing evidence on experimental vaginal microbicides for prevention of HIV acquisition in women. There are substantive differences between the current systematic review and the Cochrane review of topical microbicides for prevention of sexually transmitted infections [42]. Firstly, we have included all trials of experimental vaginal microbidides tested to date; but the Cochrane review excluded trials that assessed the effects of nonoxynol-9. Secondly, the current review assessed the effects of experimental microbicides on HIV acquisition while the Cochrane review focused on sexually transmitted infections. Thirdly, the current review included only studies that enrolled heterosexual women who were HIV-negative at enrolment whereas the Cochrane review searched for studies involving heterosexual women or men who have sex with men who had no evidence of sexually transmitted infections at enrolment. Finally, the current review includes a quantitative synthesis of all currently available effectiveness data from experimental vaginal microbicides; but the Cochrane review conducted a narrative synthesis of effects across the different classes of non-nonoxynol-9 microbicides. 


\section{Conclusions}

At present, limited evidence suggests that vaginal microbicides containing tenofovir - a nucleotide reverse transcriptase inhibitor - may reduce HIV acquisition in heterosexual women; but other types of vaginal microbicides have not shown evidence of an effect. Therefore, there is not enough evidence to recommend vaginal microbicides for HIV prevention at present. Further randomised controlled trials are needed to confirm the beneficial effects of the tenofovir gel. In addition, further research should continue on the development and testing of new microbicides.

\section{Competing interests}

The authors have declared that they have no competing interests.

\section{Authors' contributions}

JO and CSW conceived the review, selected studies, extracted and analysed data, and wrote the first draft of the manuscript. PGM and GDH contributed to the interpretation of the results and critical revisions of the manuscript. All authors read and approved the final manuscript.

\section{Acknowledgements}

We are grateful to Tonantzin Ribeiro (Cochrane sexually Transmitted infection Group) and Joy Oliver (Cochrane HIV/AIDS Group) for assistance with the development and implementation of search strategies used in this review. We are also grateful for the advice received from Professor Cate Hankins, Chief Science Advisor to UNAIDS.

\section{Author details}

${ }^{1}$ Department of Reproductive Health and Biology, Institute of Primate Research, Karen Road, Nairobi, Kenya. ²Department of Medical Microbiology, University of Nairobi, Off Ngong Road, Nairobi, Kenya. ${ }^{3}$ Vaccines for Africa Initiative, Institute of Infectious Disease and Molecular Medicine, University of Cape Town, Observatory, Cape Town, South Africa. ${ }^{4}$ Division of Medical Microbiology, Department of Clinical Laboratory Sciences, University of Cape Town, Observatory, Cape Town, South Africa.

Received: 31 October 2012 Accepted: 2 November 2012 Published: 6 November 2012

\section{References}

1. UNAIDS: Global report, UNAIDS report on the global AIDS epidemic 2010. UNAIDS/10.11E / JC1958E. Joint United Nations Programme on HIV/ AIDS.

2. Carpenter CC, Cooper DA, Fischl MA, Gatell JM, Gazzard BC, Hammer SM Hirsch MS, Jacobsen DM, Katzenstein DA, Montaner JS, Richman DD, Sag MS, Schechter M, Schooley RT, Thomson MA, Vela S, Yeni PG, Volberding PA: Antiretroviral therapy in adults: updated recommendations of the International AIDS Society-USA Panel. JAMA 2000, 283:381-390.

3. Trabattoni D, Lo Caputo S, Biasi M, Seminari E, Di Pierto M, Ravasin G, Mazota F, Maserati R, Clerici M: Modulation of human immunodeficiency virus IHIV)-specific immune response by using efavirenz, nelfinavir, and stavudine in a rescue therapy regimen for HIV-infected, drug-experienced patients. Clin Diagn Lab Immunol 2000, 9:1114-1118.

4. Letvin NL: Progress and obstacles in the development of an AIDS vaccine. Nat Rev Immunol 2006, 6:541-552.

5. Wiysonge CS, Shey MS, Kongnyuy EJ, Brocklehurst P: Vaginal microbicide for preventing mother-to-child transmission of HIV infection: no evidence of an effect or evidence of no effect? S Afr Med J 2007, 97:530-533.

6. Cohen MS, Chen YQ, McCauley M, Gamble T, Hosseinipour MC, Kumarasamy N, Hakim JG, Kumwenda J, Grinsztejn B, Pilotto JH, Godbole SV, Mehendale S, Chariyalertsak S, Santos BR, Mayer $\mathrm{KH}$ Hoffman IF, Eshleman SH, Piwowar-Manning E, Wang L, Makhema J, Mills LA, de Bruyn G, Sanne I, Eron J, Gallant J, Havlir D, Swindells S, Ribaudo H, Elharrar V, Burns D, Taha TE, Nielsen-Saines K, Celentano D, Essex M, Fleming TR, HPTN 052 Study Team: Prevention of HIV-1 infection with early antiretroviral therapy. N Engl J Med 2011, 365:493-505.
7. Siegfried N, Muller M, Deeks JJ, Volmink J: Male circumcision for prevention of heterosexual acquisition of HIV in men. Cochrane database of systematic reviews 2009, (2). doi:10.1002/14651858.CD003362.pub2. Art. No.: CD003362.

8. Wiysonge CS, Kongnyuy EJ, Shey M, Muula AS, Navti OB, AkI EA, Lo Y-R: Male circumcision for prevention of homosexual acquisition of HIV in men. Cochrane Database of Systematic Reviews 2011, (6). doi:10.1002/ 14651858.CD007496.pub2. Art. No.: CD007496.

9. Elias C, Coggins C: Female controlled methods to prevent sexual transmission of HIV. AIDS 1996, 10:S43-S51.

10. Watts C, Zimmerman C: Violence against women: global scope and magnitude. Lancet 2002, 359:1232-1237.

11. Higgins JPT, Green S (Eds): Cochrane handbook for systematic reviews of interventions version 5.1.0 [Updated march 2011], The Cochrane collaboration; 2011. Available from www.cochrane-handbook.org.

12. Mantel N, Haenszel W: Statistical aspects of the analysis of data from retrospective studies of disease. J Natl Cancer Inst 1959, 22:719-748.

13. Higgins JPT, Thompson SG, Deeks JJ, Altman DG: Measuring inconsistency in meta-analyses. BMJ 2003, 327:557-560

14. DerSimonian R, Laird N: Meta-analysis in clinical trials. Control Clin Trials 1986, 7:177-188

15. Kreiss J, Ngugi E, Holmes KK, Ndinya-Achola J, Waiyaki P, Roberts PL, Ruminjo I, Sajabi R, Kimata J, Fleming TR, Anzala A, Holton D, Plummer F: Efficacy of nonoxynol-9 contraceptive sponge use in preventing heterosexual acquisition of HIV in Nairobi prostitutes. JAMA 1992, 268:477-482.

16. Roddy RE, Zekeng L, Ryan KA, Tamoufe U, Tweedy KG: Effect of nonoxynol-9 gel on urogenital gonorrhea and chlamydial infection: a randomised controlled trial. JAMA 2002, 287:1117-1122.

17. Roddy R, Zekeng L, Ryan K, Tamoufe U, Weir S, Wong E: A controlled trial of nonoxynol-9 film to reduce male-to-female transmission of sexually transmitted diseases. N Engl J Med 1998, 339:504-510.

18. Van Damme L, Ramjee G, Alary M, Vuylsteke B, Chandeying V, Rees H, Sirivongrangson $P$, Mukenge-Tshibaka L, Ettiègne-Traoré V, Uaheowitchai $C$, Karim SS, Mâsse B, Perriëns J, Laga M, COL-1492 Study Group: Effectiveness of COL-1492, a nonoxynol-9 vaginal gel, on HIV-1 transmission in female sex workers: a randomised, controlled trial. Lancet 2002, 360:962-964.

19. Richardson BA, Lavreys L, Martin HL, Stevens EC, Ngugi E, Mandaliya K, Bwayo J, Achola-Ndinya J, Kreiss JK: Evaluation of a low-dose nonoxynol-9 gel for the prevention of sexually transmitted diseases. Sex Transm Dis 2001, 28:394-400.

20. Feldblum PJ, Adeiga A, Bakare R, Wevill S, Lendvay A, Obadaki F, Olayemi MO, Wang L, Nanda K, Rountree W: SAVY vaginal gel (C31G) for prevention of HIV infection: A randomized controlled trial in Nigeria. PLoS One 2008, 3:e1474.

21. Halpern V, Ogunsola F, Obunge O, Wang CH, Onyejepu N, Oduyebo O, Taylor D, McNeil L, Mehta N, Umo-Otong J, Otusanya S, Crucitti T, Abdellati S: Effectiveness of cellulose sulfate vaginal gel for the prevention of HIV infection: Results of a phase III trial in Nigeria. PLoS One 2008, 3:e3784.

22. McCormack S, Ramjee G, Kamali A, Rees H, Crook AM, Gafos M, Jentsch U, Pool R, Chisembele M, Kapiga S, Mutemwa R, Vallely A, Palanee T, Sookrajh Y, Lacey CJ, Darbyshire J, Grosskurth H, Profy A, Nunn A, Hayes R, Weber J: PRO2000 vaginal gel for prevention of HIV-1 infection (Microbicides Development Programme 301): a phase 3, randomised, double-blind, parallel-group trial. Lancet 2010, 376:1329-1337.

23. Peterson L, Nanda K, Opoku BK, Ampofo WK, Owusu-Amoako M, Boakye AY, Rountree W, Troxler A, Dominik R, Roddy R, Dorflinger L: SAVVY (C31G) gel for prevention of HIV infection in women: A phase 3, double-blind, randomized, placebo-controlled trial in Ghana. PLOS One 2007, 2(Suppl 12):e1312

24. Van Damme L, Govinden R, Mirembe FM, Guédou F, Solomon S, Becker ML, Pradeep BS, Krishnan AK, Alary M, Pande B, Ramjee G, Deese J, Crucitti T, Taylor D, CS Study Group: Lack of effectiveness of cellulose sulfate gel for the prevention of vaginal HIV transmission. N Engl J Med 2008, 359:463-473.

25. Abdool Karim Q, Abdool Karim SS, Frohlich JA, Grobler AC, Baxter C, Mansoor LE, Kharsany AB, Sibeko S, Mlisana KP, Omar Z, Gengiah TN, Maarschalk S, Arulappan N, Mlotshwa M, Morris L, Taylor D, CAPRISA 004 Trial Group: Effectivness and safety of tenofovir gel, an antiretroviral microbicide, for the prevention of HIV infection in women. Science 2010, 329:1168-1174. 
26. Abdool Karim SS, Richardson BA, Ramjee G, Hoffman IF, Chirenje ZM, Taha T, Kapina M, Maslankowski L, Coletti A, Profy A, Moench TR, Piwowar-Manning E, Mâsse B, Hillier SL, Soto-Torres L, HIV Prevention Trials Network (HPTN) 035 Study Team: Safety and effectiveness of BufferGelB and $0.5 \%$ PRO2000 gel for the prevention of HIV infection in women. AIDS 2011, 25:957-966.

27. Skoler-Karpoff S, Ramjee G, Ahmed K, Altini L, Plagianos MG, Friedland B, Govender S, De Kock A, Cassim N, Palanee T, Dozier G, Maguire R, Lahteenmaki P: Efficacy of Carraguard for prevention of HIV infection in women in South Africa: a randomised, double-blind, placebo-controlled trial. Lancet 2008, 372:1977-1987.

28. Safety and effectiveness of tenofovir $1 \%$ gel, tenofovir disproxil fumarate, and emtricitabine/tenofovir disoproxil fumarate tablets in preventing HIV in women. http://www.Clinicaltrials.gov/show/ NCT00705679.

29. NCT01386294: Safety and effectiveness of tenofovir gel in the prevention of human immunodeficiency virus (HIV-1) infection in young women and the effects of tenofovir gel on the incidence of herpes simplex virus (HSV-2) infection. http://www.Clinicaltrials.gov/show/NCT01386294.

30. Cutler JC, Singh B, Carpenter U, Nickens O, Scarola A, Sussman N, Wade M, Volkin L, Marsico A, Balinsky H: Vaginal contraceptives as prophylaxis against gonorrhoea and other sexually transmissible diseases. Adv Plan Parenthood 1977, 12:45-56.

31. Rendon AL, Covarrubias J, McCarney KE, Marion-Landais G, Luna del Villar A controlled comparative study of phenylmercuric acetate, nonoxynol-9 and placebo vaginal suppositories as prophylactic agents against gonorrhoea. Curr Therap Res 1980, 27:780-783.

32. Rosenberg MJ, Rojanapithayakorn W, Feldblum PJ, Higgins JE: Effect of the contraceptive sponge on chlamydial infection, gonorrhoea, and candidiasis. A comparative clinical trial. JAMA 1987, 257:780-783.

33. Louv WC, Austin H, Alexander WJ, Stagno S, Cheeks J: A clinical trial of nonoxynol-9 for preventing gonococcal and chlamydial infection. $J$ Infect Dis 1988, 158:518-523.

34. Barbone F, Austin H, Louv WC, Alexander WJ: A follow-up study of methods of contraception, sexual activity, and rates of trichomoniasis, candidiasis, andbacterial vaginosis. Am J Obstet Gyncol 1990, 163:510-514.

35. Niruthisard S, Roddy RE, Chutivongse S: Use of nonoxynol-9 and reduction in rate of gonococcal and chlamydial cervical infections. Lancet 1992, 339:1371-1375.

36. van der Straten A, Napierala S, Cheng H, Mauck C, Depineres T, Dhlakama P, Thompson M, Chipato T, Hammond N, Padian N: A randomized controlled safety trial of the diaphragm and cellulose sulphate microbicide gel in sexually active women in Zimbabwe. Contraception 2007, 76:389-399.

37. Buckheit RW Jr, Watson KM, Morrow KM, Ham AS: Development of topical microbicides to prevent the sexual transmission of HIV. Antiviral Res 2010, 85:142-158.

38. Cutler B, Justman J: Vaginal microbicides and the prevention of HIV transmission. Lancet Infect Dis 2008, 8:685-697.

39. Garg AB, Nuttall J, Romano J: The future of HIV microbicides: challenges and opportunities. Antivir Chem Chemother 2009, 19:143-150.

40. Klasse PJ, Shattock R, Moore JP: Antiretroviral drug-based microbicides to prevent HIV-1 sexual transmission. Annu Rev Med 2008, 59:455-471.

41. Nuttall J: Microbicides in the prevention of HIV infection: current status and future directions. Drugs 2010, 70:1231-1243.

42. Obiero J, Mwethera PG, Wiysonge CS: Topical microbicides for prevention of sexually transmitted infections. Cochrane Database Syst Rev 2012, (6). doi:10.1002/14651858.CD007961.pub2. Art. No.: CD007961.

doi:10.1186/1471-2334-12-289

Cite this article as: Obiero et al:: Vaginal microbicides for reducing the risk of sexual acquisition of HIV infection in women: systematic review and meta-analysis. BMC Infectious Diseases 2012 12:289.

\section{Submit your next manuscript to BioMed Central and take full advantage of:}

- Convenient online submission

- Thorough peer review

- No space constraints or color figure charges

- Immediate publication on acceptance

- Inclusion in PubMed, CAS, Scopus and Google Scholar

- Research which is freely available for redistribution

Submit your manuscript at www.biomedcentral.com/submit
C Biomed Central 